\title{
ArcheoSciences
}

Revue d'archéométrie

33 (suppl.) | 2009

Mémoire du sol, espace des hommes

\section{Characterisation of the structural heterogeneity of the soil layer by using in situ 2D and 3D electrical resistivity measurements}

M. Seger, I. Cousin, G. Giot, H. Boizard, F. Mahu and G. Richard

\section{OpenEdition}

Journals

Electronic version

URL: https://journals.openedition.org/archeosciences/1822

DOI: 10.4000/archeosciences. 1822

ISBN: 978-2-7535-1599-4

ISSN: $2104-3728$

Publisher

Presses universitaires de Rennes

Printed version

Date of publication: 30 October 2009

Number of pages: $349-351$

ISBN: 978-2-7535-0943-6

ISSN: $1960-1360$

Electronic reference

M. Seger, I. Cousin, G. Giot, H. Boizard, F. Mahu and G. Richard, "Characterisation of the structural heterogeneity of the soil layer by using in situ 2D and 3D electrical resistivity measurements", ArcheoSciences [Online], 33 (suppl.) | 2009, Online since 30 October 2011, connection on 21 September 2021. URL: http://journals.openedition.org/archeosciences/1822 ; DOI: https://doi.org/10.4000/ archeosciences. 1822 


\title{
Characterisation of the structural heterogeneity of the soil layer by using in situ $2 \mathrm{D}$ and $3 \mathrm{D}$ electrical resistivity measurements
}

\author{
M. Seger*, I. Cousin*, G. Giot* ${ }^{*}$, H. Boizard ${ }^{* *}$, F. Mahu ${ }^{* *}$ and G. Richard ${ }^{*}$
}

Key words: Soil structure, Electrical resistivity, Tillage, Compaction, soil physics studies

\section{INTRODUCTION}

Soil structure i.e. the arrangement of soil particles in space (Guérif, 1987) is one important factor of physic quality of soils. In the agricultural context, this structure is modified at several space and time scales by different constraints or processes: tillage, compaction by traffic, natural effects. We need methods to characterize its in situ state. They already exist but they are destructive and time consuming. Recent works (Besson et al., 2004) have shown that a compacted band in loose material can be characterised by a $2 \mathrm{D}$ electrical resistivity prospecting. Our objective, in this study, is to examine the feasibility of characterizing a complex structure of a cultivated soil by using a three-dimensional electrical resistivity method. Results of resistivity measurements will be compared with the characterisation of soil structure by measurements of bulk density and morphological profiles.

\section{Material AND METHOdS}

\section{Experimental site}

The experiment was conducted on a subplot of $2,40 \mathrm{~m} \times$ 2,40 $\mathrm{m}$ on a typical Luvisol at the INRA Centre of Estrées-
Mons (Somme, France). We created a compacted band by wheeling at field capacity. Then, ploughing was performed in order to fragment the compacted band to produce zones with a complex and natural arrangement of compacted clods (named $\Delta$ clods), loose material and large voids.

\section{Electrical resistivity measurements}

Numerous measurements were realised thanks to multielectrodes system and pre-recorded sequences of quadripoles. Profiles of tomography were realised with two types of array: i) the Wenner array and ii) the square array (Fig. 1). Five Wenner arrays (WEN1 to WEN5), were realised in a direction parallel to the traffic direction (Oy direction). Five square arrays (SQ1 to SQ5) were constituted of bands of 12 electrodes whose inter-electrode spacing was equal to $0,10 \mathrm{~m}$ or $0,20 \mathrm{~m}$. The current was injected in the $\mathrm{Oy}$ direction or in the Ox direction. The apparent resistivity measurements from the square arrays were analysed with the use of the AAI index (Samouëlian et al., 2004). Apparent resistivity measurements recorded from the Wenner and the square arrays were inverted to produce $2 \mathrm{D}$ and $3 \mathrm{D}$ interpretations. The soil temperature was recorded during the experiment. As it did not vary significantly from the soil surface to $30 \mathrm{~cm}$ depth, the resistivity measurements were not corrected for the temperature.

*INRA, UR0272 Science du Sol, Centre de recherche d'Orléans, 2163 Avenue de la Pomme de Pin, CS 40001 Ardon, F-45075 Orléans cedex 2 , France.

** INRA, UR1158 Agro-Impact, 2 Chaussée Brunehaut, Estrées-Mons, BP 50136, F-80203 Péronne, France. 


\section{Characterisation of the soil structure}

Once the electrical measurements were recorded, ten morphological profiles (P1-P10), perpendicular to the wheel track were analysed (see positions in Fig. 1). The association of all these profiles enabled to describe the $3 \mathrm{D}$ organisation of the zones with different degrees of compaction. Samples were realised to measure the bulk density and the water content into soil profiles.
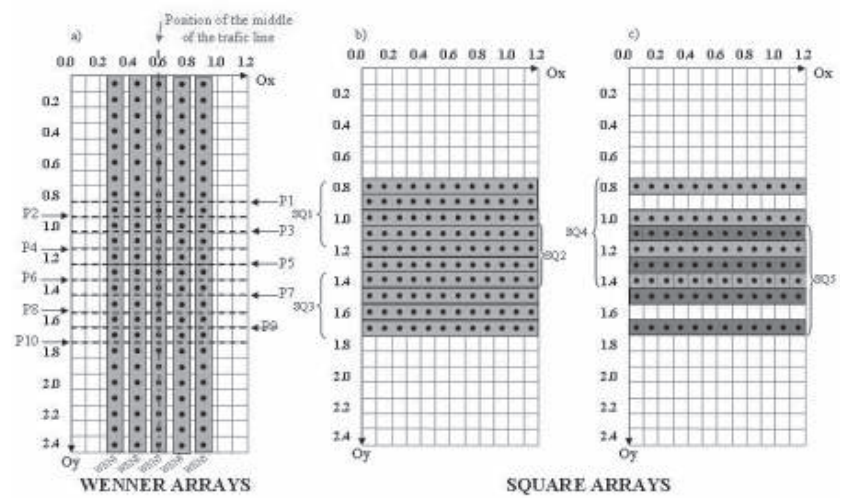

Figure 1 (see color plate): Design of the experiment on the studied subplot. a) Position of the Wenner arrays and of the morphological profiles. b) Position of the square arrays with an inter-electrode spacing equal to $10 \mathrm{~cm}$ (SQ1-SQ3). c) Position of the square arrays with an inter-electrode spacing equal to $20 \mathrm{~cm}$ (SQ4-SQ5).

\section{RESULTS AND DISCUSSION}

\section{Characterisation on soil structure}

The visual analysis of the morphological profiles (Fig. 2) shows that tillage and traffic result in different types of soil structure. Despite local variations, the spatial soil structure was identical whatever the morphological profile, along the Ox. However, it was strongly heterogeneous along the $\mathrm{Oy}$ direction. Three zones can be identified (see Fig. 2):

loose material and a large $\Delta$ clod at about $10 \mathrm{~cm}$ depth, complex structure with $\Delta$ clods of varying sizes embedded in loose material and surrounded by cracks,

loose material with few centimetric $\Delta$ clods.

The complexity of the general 3D organisation of the soil structure questions the representativity of only one profile to describe it. The bulk density was significantly higher in the $\Delta$ clods but not the water content.

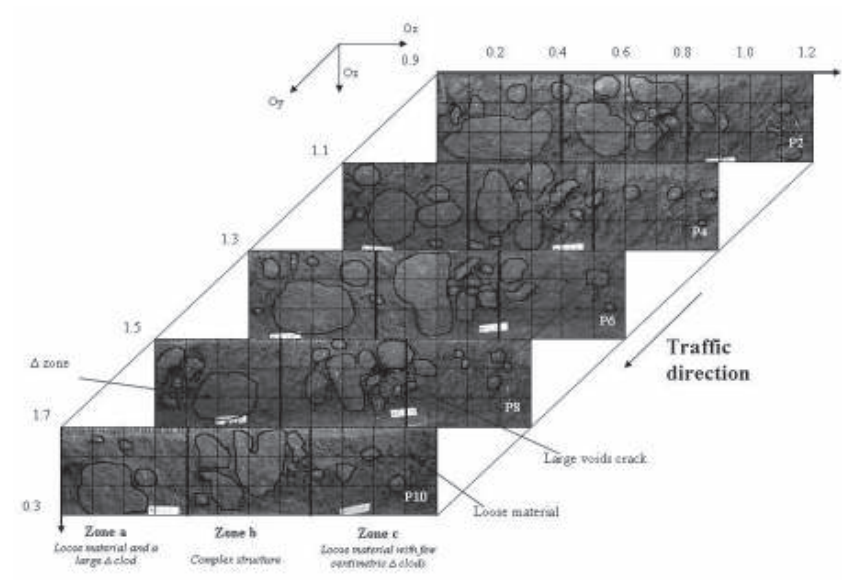

Figure 2: Visual morphological profiles P2, P4, P6, P8, P10. $\Delta$ zones are surrounded by the black lines.

\section{Electrical resistivity measurements}

The 2D profiles from the apparent and interpreted electrical resistivity values (WEN1 to WEN5) exhibited the same 3 classes for measurements near the soil surface: the WEN3 and WEN4 measurements resulted in high resistivity values with high variability. The WEN1 and WEN2 arrays showed lower values of resistivity with a lower variability. The WEN5 exhibited intermediate values, but the resistivity was higher in the left part of the profile than in the right part. The resistivities at the soil surface vary significantly from one Wenner array to another.

The analyse of the apparent electrical resistivity values recorded by the square arrays SQ1 to SQ5 (3D tomography) showed for the third pseudo-depth a great heterogeneity, whatever the direction of injection for the current: 20 to $300 \Omega \mathrm{m}$. The mean resistivity was significantly higher when the current was injected in the Ox direction than when it was injected in the $\mathrm{Oy}$ direction. The AAI index showed an electrical anisotropy along the traffic line (AAI $>0$ ) whereas it was usually close to 0 far from the traffic line.

All the apparent resistivity measurements obtained from the Wenner arrays and from the square arrays were gathered and interpreted (Fig. 3). These results demonstrated a strong heterogeneity of the cultivated layer with a specific spatial organisation: alternative bands of high and low resistivity, oriented along the Oy axis.

Comparisons between 2D and $3 \mathrm{D}$ values showed the same order of magnitude but differences due to (i) differences between geometry of the positions of the electrodes and

(ii) differences between the volumes of soil prospected. 


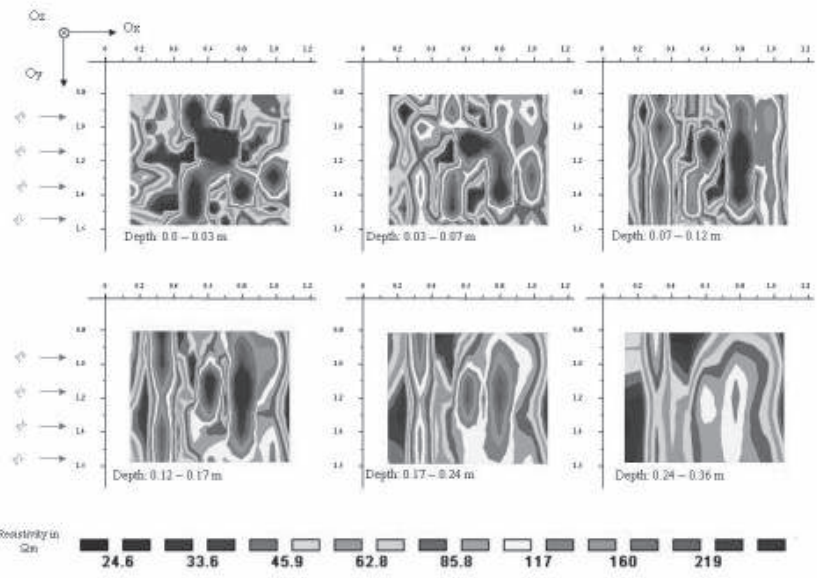

Figure 3 (see color plate): 3D interpreted electrical resistivity. The original data from all the arrays have been inverted by the RES3DINV software. Each map represents the inverted resistivity at different dephts. The grey arrows represent the position of some morphological profiles.

\section{Relationships between the soil structure and the electrical resistivity measurements}

The $\Delta$ clods and the loose material were respectively associated to resistivity of about $25-30 \mathrm{ohm} . \mathrm{m}$ and $50 \mathrm{ohm} . \mathrm{m}$. The highest values, larger than $70 \mathrm{ohm} . \mathrm{m}$ corresponded to large voids surrounding $\Delta$ clods. The difference in resistivity due to voids, even relatively small ones, makes difficult the interpretation of electrical resistivity in terms of soil structure. The depths calculated by the inversion protocol are relevant, both for the $2 \mathrm{D}$ and $3 \mathrm{D}$ inversions.

Moreover, the general orientation of the heterogeneities detected by the $3 \mathrm{D}$ was consistent with the direction of the traffic and the main heterogeneities observed on the morphological profiles.

\section{Conclusion}

The aim of this study was to discuss the feasibility of 3D electrical resistivity measurements to characterise the $3 \mathrm{D}$ structure of the cultivated layer in situ. Both the $2 \mathrm{D}$ and $3 \mathrm{D}$ prospectings have enabled to identify compacted zones, loose material, or clods embedded by voids. The position of these structures can be determined by the electrical measurements but their exact geometrical characterisation can not be described neither from the apparent resistivity data, nor by the interpreted resistivity. The $3 \mathrm{D}$ images, provided both by electrical prospecting and morphological profiles, will help in modelling water transfer as well as root architecture and seedling emergence.

\section{References}

Besson, A., Cousin, I., Samouëlian, A., Boizard, H., Richard, G., 2004. Structural heterogeneity of the soil tilled layer as characterized by 2D electrical resistivity surveying. Soil \& Tillage Research, 79: 239-249.

GuÉrIF, J., 1987. L'analyse de la porosité : Application à l'étude du compactage des sols. In Monnier, G., Goss, M. J., (dir.), Soil compaction and regeneration, CEC Worshop on soil compaction/Avignon 17-18 Sept. 1985, 1-13.

Samouëlian, A., Richard, G., Cousin, I., Guérin, R., Bruand, A., Tabbagh, A., 2004. Three dimensional crack monitoring by electrical resistivity measurement. European Journal of Soil Science, 55: 751-762. 